\title{
INSIGHTS INTO CHRONONUTRITION: THE INNERMOST INTERPLAY AMONGST NUTRITION, METABOLISM AND THE CIRCADIAN CLOCK, IN THE CONTEXT OF EPIGENETIC REPROGRAMMING
}

\author{
CRISTINA MANUELA DRĂGOI ${ }^{1 /}$, ELENA MOROŞAN ${ }^{1 *}$, ION-BOGDAN DUMITRESCU $^{1 *}$, \\ ALINA CRENGUȚA NICOLAE ${ }^{1}{ }^{*}$, ANDREEA LETIŢIA ARSENE ${ }^{1 *}$, DOINA DRĂGĂNESCU ${ }^{1}$, \\ DUMITRU LUPULIASA ${ }^{1}$, ANA CORINA IONIŢA ${ }^{1}{ }^{1}$, ANCA PANTEA STOIAN ${ }^{1}$, CAMELIA \\ NICOLAE $^{1 \#}$, MANFREDI RIZZO $^{2,3}$, MAGDALENA MITITELU $^{1}$ \\ 1 "Carol Davila” University of Medicine and Pharmacy, Bucharest, Romania \\ ${ }^{2}$ Biomedical Department of Internal Medicine and Medical Specialties School of Medicine, University of Palermo, Palermo, Italy \\ ${ }^{3}$ Division of Endocrinology, Diabetes and Metabolism University of South Carolina School of Medicine Columbia, South \\ Carolina, United States of America
}

*corresponding author: alina.nicolae@umfcd.ro

\#Authors with equal contribution

Manuscript received: March 2019

\begin{abstract}
Chrononutrition encompasses the concepts of metabolism, nutrition and circadian synchronization, determinant processes in ensuring the dynamic energy equilibrium of the human organism. The interrelations between the external environmental modulators and the molecular, biochemical mechanisms underlying all the integrative processes are subject to permanent adjustments and become vulnerable to changes in nutritional characteristics, temperature variations or light intensity, to the detection of acute or chronic stress factors. Accordingly, it is of overwhelming importance to identify the biochemical mechanisms of transforming the dietary nutrients, the principles of energy metabolism, the particularities of nutritional states in direct interdependence with the endocrine changes that occur consequently, the nutritional ketosis and the particular characteristics of the use of ketone bodies in physiological situations, but also particular pathological conditions, and last but not least, the ambivalent impact between chronobiological factors and metabolic balance. All these facts converge towards a stable fingerprint of the epigenome on all molecular mechanisms that provide the homeostasis of the entire organism.
\end{abstract}

\section{Rezumat}

Crononutriția înglobează conceptele de metabolism, nutriție și sincronizare circadiană, procese determinante în asigurarea echilibrului energetic dinamic al organismului uman. Interrelațiile existente între factorii modulatori din mediu exterior și mecanismele biochimice moleculare ce stau la baza tuturor proceselor integratoare sunt suspuse unor ajustări permanente şi devin vulnerabile la schimbările caracteristicilor nutriționale, la variațiile de temperatură sau a intensității luminoase, la detectarea unor factori de stres acut sau cronic. Astfel, este de o importanță deosebită cunoașterea mecanismelor biochimice de transformare a nutrienților proveniți din dietă, a principiilor metabolismului energetic, a particularităţilor stărilor nutriționale, în interdependență directă cu modificările endocrine ce survin în consecință, cetoza nutrițională și caracteristicile speciale ale utilizării corpilor cetonici în situații fiziologice dar și în conjuncturi patologice particulare, și nu în ultimul rând, impactul echivoc existent între factorii cronobiologici și echilibrul metabolic. Toate acestea converg către o amprentă puternică a epigenomului asupra tuturor mecanismelor moleculare ce asigură homeostazia întregului organism.

Keywords: chrononutrition, epigenome, ketosis, metabolic balance, nutrition, chronobiology, circadian rhythm

\section{Fundamental biochemical pathways that delineate the energy metabolism}

Nutrients that sustain the energy homeostasis of the human organism

Human metabolism represents a complex network of interconnected biochemical reactions driven by the organism for transforming exogenous/dietary or endogenous molecules in order to gain energy and structurally useful smaller components. The significant principles of metabolism regulation are conserved in all forms of life denoting their importance in all aspects of cellular cycles of development, evolution, reproduction and death. Nevertheless, imbalances between the metabolic requests and the metabolic capability of an organism, results in its inability to adapt day by day to the given environmental changing conditions. There are associated with an extensive range of pathologies, including metabolic syndrome, obesity, diabetes, cardiovascular diseases, tumorigenesis and neurodegeneration. All organisms rely on their communication with environmental sensors, their interaction with outlining factors, competing with external challenges and their capacity to predict them 
and simultaneously adapt to new settings dictates how organisms overpass the intricacy states [8, 20, 34]. The human organism relies on carbohydrates, lipids, and proteins as principal components of food that serve as energetic molecules. Their digestion at different levels in the alimentary tract, meant to break down to components the large structures of these nutrients and the subsequent absorption of small metabolites finalized with their passage in the blood- stream, create the conditions for tissues and cells to convert the potential chemical energy of nutrients into readily available macroergic constituents [50]. The primary final products of nutrients digestion are simple saccharides, mostly glucose, that arise from carbohydrates digestion, glycerol and fatty acids that are obtained from lipids intestinal enzymatic processing and small peptides and amino acids, from exogenous proteins (Figure 1).

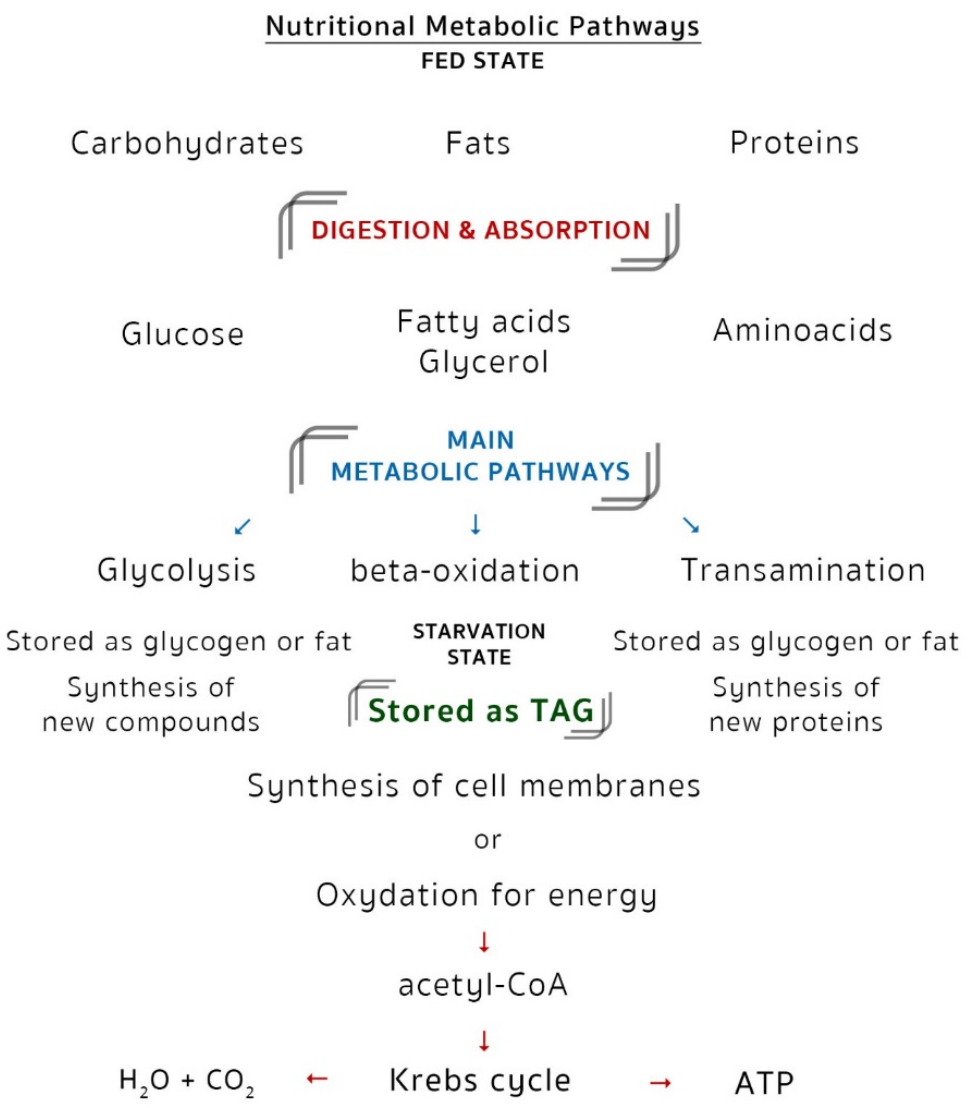

Figure 1.

Biochemical pathways implicated in energy metabolism

All nutritional constituents of the dietary regimen undergo digestion and absorption processes, specific for every class: carbohydrates, lipids, and proteins, generate small metabolites that can pass in to the bloodstream and are further biochemically degraded through particular pathways that all converge to acetyl-CoA production that is transformed in the tricarboxylic acids cycle in energy, $\mathrm{CO}_{2}$ and $\mathrm{H}_{2} \mathrm{O}$.

Even though carbohydrates are not critical constituents of the diet, they usually represent almost $45-55 \%$ of the total daily human caloric intake. After carbohydrates digestion, the subsequent monosaccharides are rapidly absorbed by enterocytes, but being polar molecules, special transporters are required in order to cross cell membranes. There are specific transport mechanisms for different monosaccharides in order to be able to target the requiring tissues. It is acknowledged that each cell of the body expresses one or more types of GLUT transporters, granting the role of glucose as the major molecular fuel resource $[8,45]$.

The particular tissue dependence on carbohydrate metabolism is reflected by the type of GLUT carrier expressed in each cell. For instance, tissues and cells that exclusively depend on glucose as an energy substrate, such as erythrocytes and endothelial cells of the brain, have higher concentrations of GLUT1 transporters with a high affinity for glucose, realizing an effective absorption even at extremely low glycaemia levels. The same transporter is also mediating the transport of glucose to the placenta, is highly requisite for all foetal development processes. The liver, kidneys, pancreas and intestine, as tissues massively involved in the absorption and regulation 
FARMACIA, 2019, Vol. 67, 4

of blood glucose, express primarily the GLUT2 transporter, displaying a lower affinity for glucose, becoming more active at high glucose concentrations, and being responsible for high blood pressure the glucose level, leading to its physiological role independent of the insulin regulation action [43, 45].

Adipocytes, myocytes and cardiomyocytes principally express the insulin-dependent glucose transporter GLUT4, which becomes sensitive only at high glucose concentrations and as a response to excessive insulin levels.

As a consequence of insulin interaction with its specific membrane receptors, the GLUT4 transporters are translocated from the intracellular compartment to the cell membrane, permitting glucose to access the cell. After being transported into insulin-sensitive cells, glucose can follow two different passageways: either it is catabolized or converted to glycogen, both having the same determination to maintain normal glucose tolerance. The disruption of this translocation phenomenon is one of the mechanisms implied by the development of insulin resistance, also contributing to type 2 diabetes progress. Diabetic patients are displaying a significantly reduced expression of GLUT4, indicating a particular reduced capability to metabolize glucose (Figure 2).

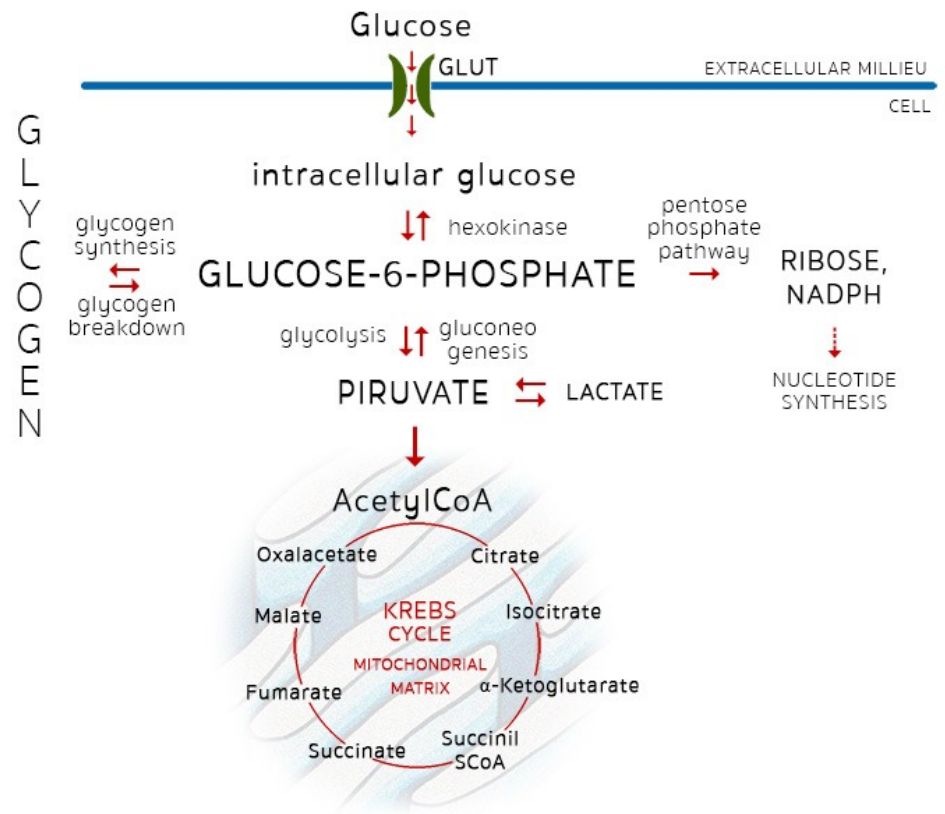

Figure 2.

The emblematic molecular mechanisms of glucose transformation in energy metabolism

Intracellular glucose is further phosphorylated by hexokinase, a salient enzyme for the whole energy metabolism. Glucose 6-phosphate, the resulting biologically activated form of glucose, is the originator molecule for numerous metabolic paths that can further initiate, the main important being glycolysis, but at a certain extent, pentose phosphate pathway and glycogen synthesis also contribute to retaining glucose intracellularly and to maintaining a concentration gradient that enables the continuous access of glucose into the cell. Further metabolic steps are dependent on the presence of oxygen in the cellular environment. Another sine qua non-condition, in order to perform ATP (adenosine triphosphate) synthesis, is the presence of the unique mitochondrial machinery. Therefore, in aerobic conditions, pyruvate is intramitochondrially oxidized to acetyl-CoA, which further enters the Krebs cycle, is metabolized to $\mathrm{CO}_{2}$ and generating ATP after several chemical transformations and the synergy with the electron transport chain $[8$, $21]$.

In anaerobic state or in the absence of mitochondria, as it's the case of erythrocytes, pyruvate is transformed to lactate by the enzyme lactate dehydrogenase, then released into the bloodstream and transported to tissues that can use it as an energy source or can be hepatically reversed to glucose, metabolic recycling process known as the Cori cycle [8, 50, 67].

The emblematic importance of glucose in the energyproducing mechanisms is demonstrated by the existence of special enzymatic equipment of the mammalian cells that confers the capacity to accumulate glucose in the readily accessible form of glycogen. The largest and most important provisions of glycogen are established in the liver and skeletal muscle, allowing a constant physiological blood glucose concentration and for providing an energy deposit rapidly accessible in the case of decreased glycaemia. 
FARMACIA, 2019, Vol. 67, 4

Regarding the protein metabolism, the total protein intake is around $15-20 \%$ of the total daily caloric intake considering a healthy diet, and the other significant source of proteins is represented by up to $200 \mathrm{~g}$ of endogenous protein structures that are daily degraded. The digestion process results in constituent amino acids that are further used for energy yield or for replenishing the metabolic pool of amino acids. These versatile structures of amino acids can be supplementary useful for protein synthesis and as precursors in many biosynthetic reactions. The amino acids can be reprocessed by removing the nitrogen from their chemical structure in order to be useful as substrates in the energy metabolism, each amino acid requiring a different degradation pathway. The main reactions that are metabolically essential are transamination and deamination. First, by the use of aminotransferases amino acids are converted to $\alpha$-ketoacids, allowing the amino acids to be further interconverted. By deamination, the amino groups of the amino acids are transformed into ammonia. Consequently, by this chemical metamorphosis, all amino acids are converted directly or by additional transformation to pyruvate or acetyl-CoA, into intermediates of the Krebs cycle [8, 70, 79].

The nutritional importance of lipids derives from their high prevalence in the general population daily diets, which according to statistics account for up to $35 \%$ of the calories, triacylglycerol being the dominant component, accounting to $90-95 \%$ of the total energy derived from dietary fat, the other part being represented by phospholipids, sterols, of which mainly cholesterol, and other important molecules as liposoluble vitamins (A, D, E and K) [35]. Dietary fatty acids have long-chain skeletons with over 12 atoms of carbon, usually $\mathrm{C} 16, \mathrm{C} 18$, and $\mathrm{C} 20$. On the contrary, medium-chain fatty acids that contain 8 to 12 atoms of carbon in their structure are seldom found in food and have a smaller impact on the lipids digestion and absorption. Last but not least, the short-chain fatty acids C2-C4 are not found in food, resulting exclusively from the lipids digestion by the intestinal bacteria.

Consecutive to their digestion, lipids are converted to glycerol and free fatty acids, which are taken over by the blood flow $[47,83]$.

Carbohydrates, proteins and lipids oxidative conversions congregate on the tricarboxylic acid cycle

The energy metabolism has a significant component, which is glycolysis, the emblematic metabolic pathway for glucose degradation, but we should outline the fatty acids and amino acids oxidation, as biochemical mechanisms conducted in the human body as subsequent or equally important in extreme physiological or more pronounced in pathological states [75, 79].
Living cells gain their compulsory energy by breaking the chemical links existent within the nutrient molecules, through the overall metabolic processing driven basically by connecting the oxidative processes of nutrients with the production of high-energy compounds, mainly adenosine triphosphate (ATP), the most available energetic molecule.

ATP is primarily synthesized from ADP (adenosine diphosphate) and inorganic phosphate by the intricate mitochondrial oxidative phosphorylation and furthermore on substrate phosphorylation, a process that implies the transfer of phosphoryl groups from macroergic compounds to ADP $[8,65]$.

In aerobic conditions, all bio-compounds achieved consecutively to the nutrients degradation are driven uniquely to the Krebs cycle, the pivotal metabolic point, which ultimately conveys the acetyl-CoA resultant from the glucose catabolism, several amino acids and fatty acids to $\mathrm{CO}_{2}$ and $\mathrm{H}_{2} \mathrm{O}$.

The glucose-fatty acids dynamic balance is a powerful endogenous instrument that reins energy substrate selection and finely adjusts the offer-request ratio in common tissues in perfect synchronization with endocrine signals and hormones availability in the blood circulation.

\section{Considerations on the human nutritional states: fed, fasted, starvation}

\section{The fed state}

The fed state is the metabolic period after every meal characterized by the transport of glucose and amino acids from the intestinal tract to the circulatory system and the transformation of dietary lipids in chylomicrons and their blood attainment with the support of the lymphatic system. This circumstance is best defined by the secretion of insulin, a remarkable endocrine regulator of the energy metabolism that has antagonistic effects with glucagon, together with establishing the finely tuned equilibrium between fed and fasted states. The pancreatic secretion of insulin is stimulated by high glucose levels and the parasympathetic nervous system, signalling the cascade of metabolic changes distinctive for the fed state: energy storage and protein synthesis initiation $[8,84]$.

All its actions are concurrent to the same intent: insulin launches protein kinase activation, which will arouse the muscle and liver glycogen synthesis and will defeat gluconeogenesis conducted in the hepatocytes, it will hasten the liver glycolysis which will, in consequence, intensify the fatty acids synthesis.

The hepatic tissue is a regulatory organ that strictly restraints the glycaemia range during postabsorptive states by converting it to glycogen, depot molecule that releases glucose in starvation states. The special hormonal effects on glycogen production and storing are strengthened by the direct intervention of glucose, 
which revolts the degradative glycogen machinery into a synthetic approach.

Succeeding to carbohydrates ingestion, digestion and absorption, the presence of extreme blood glucose levels trigger high insulin concentrations, initializing and sustaining the glucose access into the muscle and adipose cells, and nevertheless arousing the hepatic and muscular synthesis of glycogen. The augmented insulinemia also influences the amino acids and proteins metabolism by stimulating the muscle uptake of specific amino acids and by generally reviving protein synthesis and preventing the intracellular degradation of proteins. The glucose access into the adipocytes makes glycerol 3-phosphate available for the synthesis of triacylglycerols [8, 84].

The fasted state

The fasting state is characterized by decreasing blood glucose concentrations several hours postprandially, an abrupt decline in insulin secretion and an augmentation in glucagon secretion by the pancreatic $\alpha$ cells as a result of diminished glycaemia levels. The liver is the leading target organ of glucagon, conducting a mobilization strategy of glycogen from its stores, beginning the glycogen degradation pathway and inhibiting glycogen synthesis by promoting the cyclic AMP cascade concluded in the inhibition of glycogen synthase, the salient enzyme in this instance. Mirroring the two metabolic instances, insulin signals the fed state and glucagon signals the starved state $[3,25]$.

By reducing the production of pyruvate and decreasing acetyl CoA carboxylase activity, glucagon inhibits fatty acid synthesis, in the meantime stimulating the hepatic gluconeogenesis and blocking glycolysis by limiting the availability the fructose 2,6-bisphosphate [84].

Glucose acquired through the hydrolysis of glycogenderived glucose 6-phosphate is released into circulation from the liver, but glucose entry into myocytes and adipocytes is reduced as a result of low insulin levels. This reduced muscle and adipose tissue use of glucose also subsidize the overall process of maintaining a constant-state glucose level.

Another mechanism for sustaining glycaemia at an attired value is the capacity of the muscle and liver to use fatty acids as fuel when the levels of blood glucose decline [26, 28].

In conclusion, the average physiological glycaemia is sustained by three significant variables: the activation of glycogen degradation and the discharge of glucose by the liver, the release of fatty acids from the adipocytes, and the transition from glucose to fatty acids in the energy substrate preference by myocytes and hepatocytes. The outcome of the depletion of glycogen liver reserves is encountered in a sequence of consequences, primarily at the brain level, which entirely oxidizes glucose to $\mathrm{CO}_{2}$ and $\mathrm{H}_{2} \mathrm{O}$ [8].
The starvation state

Under starvation conditions, the carbohydrates reserves are depleted in 24 hours, but the blood-glucose level must be maintained at a minimum constant concentration.

The very first constraint of the starvation state metabolism is to assure an adequate glucose concentration to the brain and red blood cells, which undoubtedly dependent on this energy substrate. The major attainable energy is stored in triacylglycerol's fatty acyl moieties, which cannot be transformed into glucose. The glycerol structure from the triacylglycerols can be shifted to glucose, but only a limited amount is available by this route. Another significant source of glucose is constituted by amino acids arising from protein breakdown. Proteolysis provides gluconeogenesis with carbon skeletons, but degraded proteins cannot be substituted during starvation phases. Therefore, the following priority of the metabolism, in starvation states, is to maintain protein structure and functionality, which can only be attained by shifting the energy substrate from glucose to fatty acids and ketone bodies [1, 8, 17, 33, 84].

On the first day of starvation metabolic processes are comparable to those following an overnight fast period. The low level of glycaemia leads to a reduction in insulin discharge and the enhanced synthesis of glucagon. The predominant conducted biochemical actions are the mobilization of triacylglycerols from the adipocytes and the intensified hepatic gluconeogenesis. The liver increases fatty acid oxidation released from the adipose tissue, and therefore increases the levels of acetyl CoA and citrate, slowing down the glycolytic turnover. At the same time, the muscle uptake of glucose is significantly reduced due to the low level of insulin and transfers the energetic processing from glucose to fatty acids, almost completely. Muscle $\beta$-oxidation of fatty acids stops the transformation of pyruvate to acetyl $\mathrm{CoA}$; thus pyruvate, lactate, and alanine are oriented towards the liver for their transformation into glucose. Another secondary hepatic source of glucose is glycerol derived from the breakdown of triacylglycerols [20, 43, 45, 84].

The significant synthesis of ketone bodies begins after three days of starvation, the liver generating high levels of acetoacetate and $\beta$-3-hydroxybutyrate owing to its turn over from acetyl CoA which increases considerably as the Krebs cycle is ineffective in oxidizing all the acetyl molecules from the degradation of fatty acids. Furthermore, gluconeogenesis exhausts oxaloacetate, which is essential for acetyl-CoA access to the Krebs cycle.

The liver, therefore, generates enormous quantities of ketone bodies that are released into the blood, prompting the brain and also the cardiac muscle to use massive quantities of acetoacetate instead of glucose as an energetic substrate. After three days of starvation, ketone bodies fulfil up to $30 \%$ of the 
FARMACIA, 2019, Vol. 67, 4

brain's energy requirements, and after 2 - 3 weeks of starvation, ketone bodies become the brain's most significant fuel [9, 29, 32].

In summary, ketogenesis is the pathway through which ketone bodies are generated via the metabolism of fatty acids, during starvation. Ketones supply up to $50 \%$ of the primary energy needs for most tissues, in starvation and low insulinemia states, and up to $70 \%$ of the brain requirements. Although glucose is the neuron's primary metabolic substrate, ketones can satisfy the brain's energy demands. In a standard nutritional background, the ketone bodies synthesis is relatively insignificant due to the high level of insulin, which inhibits this process, concurring with the elevated concentrations of glucagon and cortisol, hormones that promote ketogenesis. Thus, low concentrations of circulating insulin, attained during starvation and diabetic ketoacidosis, represent the fundamental circumstances for ketogenesis [8, 84]. Ketone bodies are a vital source of energy for the brain, muscles, myocardium and liver. The utilization rate is a function of their concentration, elevated circulating ketone bodies levels acquired during extended fasting, accelerating their absorption dramatically.

The most important factor in regulating the rate of cerebral uptake is the plasma level of ketone bodies. Ketone bodies are hydrophilic molecules, so in order to cross the blood-brain barrier (BBB), which is fairly impermeable for these substances, a carrier protein is necessary. In this respect, monocarboxylic acid transporters (MCT1 and MCT2), originating from a family of proteins engaged in trafficking monocarboxylic acids across cell membranes, play a crucial part in the ability of ketone bodies to cross the BBB and reach neuronal cells in order to support cellular energy needs. Two mechanisms are involved in the passing sequence: diffusion and a carrier-mediated transition [58, 84]. In effect, an enhanced rate of cerebral ketone uptake and metabolism results from continuously elevated blood ketone concentrations. Cerebral ketones absorption also increases brain blood flow [37]. It should be noted that apoptosis determined cell death is diminished by the ingestion of ketones [30]. All of these biochemical mechanisms reinforce the clinical use of ketogenesis as a distinctive therapeutic strategy in refractory epilepsy, cancer, neurological disorders, metabolic diseases, oxidative status imbalances and neurodegenerative states and yet rare genetic diseases, which will be discussed extensively in a future review $[16,19,21,22,35$, $51,72,75,79,80]$.

\section{Biochemical mechanisms activated in starvation state-nutritional ketosis}

Ketone bodies synthesis and utilization by particular tissues

Acetyl-CoA generated in the liver during fatty acids oxidation may enter the Krebs cycle or transform into ketone bodies, in order to be exported to other tissues. Acetone is predominantly exhaled and is also generated in lower amounts than the other ketone bodies. Acetoacetate and $\beta$-hydroxybutyrate are transported through the blood to extrahepatic tissues where they are converted into acetyl-CoA and oxidized in the Krebs cycle, providing compulsory energy for the skeletal and cardiac muscles and the renal cortex [30, 64]. If glucose is unavailable, which is the exact case in starvation conditions, the brain, which preferably utilizes glucose as an energy source, may adapt to the use of acetoacetate or $\beta$-hydroxybutyrate. The synthesis and export of ketone bodies from the liver to extrahepatic tissues enable the sustained oxidation of fatty acids in the liver but acetyl-CoA is not oxidized in the tricarboxylic acid cycle.

In physiological conditions, acetone is formed either spontaneously or through the action of acetoacetate decarboxylase in minimal amounts from acetoacetate, which is easily decarboxylated. In decompensated diabetes, the human organism generates great amounts of acetoacetate, so in accordance, acetone, which is a harmful molecule, has important serum levels. $\beta$ hydroxybutyrate is oxidized by a $\beta$-hydroxybutyrate dehydrogenase to acetoacetate in extrahepatic tissues. Acetoacetate is activated in the form of its coenzyme A ester by transferring CoA from succinyl-CoA. Succinyl-CoA is known like an intermediate of the citric acid cycle, through a thiophorase catalysed reaction. Thiolase then cleaves the acetoacetyl-CoA to generate two acetyl-CoAs that enter the Krebs cycle. The ketone bodies are therefore used as fuels in all tissues other than the liver, which does not display thiophorase. Hence, the liver is a producer of ketone bodies for the other tissues, but never a consumer. The synthesis and distribution of ketone bodies by the liver permit the continuous oxidation of fatty acids with only negligible acetyl-CoA oxidation [30, 84-87].

Ketone bodies overproduction in diabetes and during starvation

Starvation and in the meantime, decompensated diabetes mellitus contribute to the over-production of ketone bodies, redirecting in extreme situations the metabolism to several related medical issues. Acetyl-CoA results in high amounts and its accumulation accelerates the production of ketone bodies beyond the oxidation ability of extrahepatic tissues. The elevated blood acetoacetate and $\beta$-hydroxybutyrate concentrations decrease the $\mathrm{pH}$ of the blood, 
resulting in acidosis. Extreme acidosis may lead to coma and even death in some instances.

Ketone bodies can attain exceptional concentrations in the blood and urine of patients with untreated diabetes, depicted as ketosis [57, 74]. Individuals on very low-calorie diets who use lipids stored in the adipose tissue as their primary source of energy have also elevated blood and urine concentrations of ketone bodies. In order to prevent the adverse impacts of acidosis and ketosis (ketoacidosis), these concentrations must be tightly controlled.

The role of ketone bodies in the physiological process and their pathological implications: metabolic diseases, oxidative status imbalances and neurodegenerative states, rare genetic diseases.

The oxidation of ketone bodies is a significant supplier for the general energy metabolism in extrahepatic tissues, in a myriad of physiological instances including fasting and starvation, after intense physical exercise, in neonatal periods, pregnancy and while attending low carbohydrate diets [82]. Total plasma concentrations of ketone bodies in healthy adults depict a circadian fluctuation from about $100 \mu \mathrm{M}$ to $250 \mu \mathrm{M}$, increasing to about $1 \mathrm{mM}$ after an extensive physical workout or $24 \mathrm{~h}$ fasting, but in pathological conditions such as diabetic ketoacidosis, it may accumulate as much as $20 \mathrm{mM}$ [64]. The human liver generates daily as much as $300 \mathrm{~g}$ ketone bodies, having important roles in the physiologic and pathological conditions of mammalian cell metabolism, homeostasis and signalling. Used like an energy substrate for extrahepatic tissues such as the muscle, brain, cardiovascular or skeletal systems, ketone bodies play a key role in the process of signalling, being intensively studied for their therapeutic use for multiple neurological disorders and in cancer-derived states $[5,7,15,16,22,35,72]$. They have also been assessed as metabolic drivers of post-translation protein modifications and as modulators of inflammation and oxidative stress [25, 64].

\section{Chronobiological effect of nutrition on dynamic metabolic conditions}

Human behaviour, which primarily varies depending on metabolic demands, is divided into activity (wakeful) and rest (sleep) phases, which is due to an internal oscillatory system, denoted as the circadian master clock. This temporal regulatory structure evolved into an independent control system, which aligns cognitive and behavioural strategies with environmental light and supports the functions of the body by anticipating and coordinating the metabolic features and operations needed, with a particular ability to control the multiple and complex cellular procedures $[2,23]$.

The master clock within the brain is a functional high-fidelity receiver that reacts to ambient light- darkness signals, being the central element of the synchronization mechanisms. Nevertheless, each cell of the body has a self-circadian oscillator, regulated by a master clock that converges to conferring rhythm to every cell and organ compelling a complete functional system, through excitation of rate-limiting control measures of metabolic programs, in order to accomplish the circadian control of the entire organism.

Essentially, metabolic control is not a regular circadian system output feature, but signal exerted by nutrients intake, energy turnover and the redox status represent precise feedback for cellular clocks. The circadian clock is intimately connected with the metabolic pattern, at all cellular organization and developmental levels, any insignificant misalignment in their communication channels efficiently deriving to a plethora of pathologies [44, 53].

Circadian oscillators, the central modulators of metabolic pathways

Nutrients are habitually ingested only during the light phase, thereby triggering specific modulatory mechanisms at approximately the same intervals every day that coincide with feeding periods. Being entirely driven by their regular nature, these events are extremely predictable, their recurrence depending mainly on the solar cycle. So, in order to activate precise time programmed answers to environmental stimulus, it is mandatory to develop an intrinsic, anticipatory mechanism which purely provided by the circadian clock, which developed to provide the vast majority of physiological and behavioural mechanisms with rhythmic regulation in all light-sensitive species. Circadian control is implemented and completely necessary at all levels, from single cell metabolism to complex organ function coordination, blood nutrients homeostasis and central nervous system regulation of sleep-awake sequences. A reciprocal interplay best describes the rapport between the circadian system and metabolic complex processes, being crucial in providing circadian clocks with the required flexibility to adjust physiological regimens to the metabolic needs of cells, tissues and whole organisms [12, 18, 55, 53]. Circadian clocks generate a high-fidelity inner projection of external temporal records by creating a cellular and whole organism dynamic environment that oscillates rhythmically at approximately 24 hours. Besides prompting daily rhythms, circadian clocks are sensors for environmental data that enable them to stay synchronized with day-night alterations, light and dark, hot and cold, as well as all the resources that rely on these modifications, primarily food convenience. Molecular oscillators generate 24-hour rhythmicity at the cellular level based on transcriptional-translation processes, metabolic feedback loops or their interaction. The temporal platform, which coordinates all functions to be performed at the right time within the 24-hour day, 
FARMACIA, 2019, Vol. 67, 4

involves many interacting oscillators, all of which are part of the active synchronization process portrayed as entrainment [18, 52].

Any environmental factor that varies within the 24hour day potentially can serve as an entraining signal, called zeitgeber. In the suprachiasmatic nucleus ( $\mathrm{SCN})$, a minuscule region of the brain in the hypothalamus, located directly above the optic chiasm, the dual function of circadian clocks as rhythm generators and sensors is particularly evident: it produces circadian rhythms in many of its cells, but also as a neuronal network it entrains these rhythms into the light-dark cycle through retinal feedback [23].

The SCN, often referred to as the primary pacemaker of the mammalian circadian system, serves predominantly as a relay station that transmits light and darkness data to additional oscillators present in the body by generating endogenous entrains, embodied at the molecular, physiological and behavioural level. As a central pacemaker, the SCN controls melatonin's pineal synthesis, but in the meantime, it reacts to melatonin itself, having regulatory potential on the core body temperature's daily rhythm.

A series of rhythmically expressed genes, as Bmal1 and Clock with stimulating activities, and Per1 and Cryl with inhibitory action) constitute the executive mechanism of the clock mechanism, their products representing antiphasic heterodimeric transcription factors, mandatory for generating and sustaining circadian rhythms [83].

On the other hand, Clock: Bmall also activates gene expression in families (Per) and Cryptochromes (Cry) generating a self-feed loop. The values of PERs and CRYs will increase overnight then dimerize and are translocated to the nucleus for Clock: bmal-1mediated transcription suppression. Both PERs and CRYs will undergo a series of post-translational changes that will induce their self-degradation, thus resuming a new circadian cycle.

A second important loop appears to be the involvement of REV-ERB $\alpha / \beta$ proteins. Their levels are increased during the day, linking to the specific promoter (responsive promoter elements), namely RRE, which has the role of inhibiting Bmall transcription. During the night, REV-ERB $\alpha$ protein values decrease, and so Bmal 1 transcription occurs.

These two crucial transcriptional-translational regulatory loops act on the majority of cells and control a large part of the human genome $[6,86]$.

Several well-documented proofs have shown that there are peripheral clocks, apart from the principal circadian clock in the SCN, which are governed by the master clock, considered second-order clocks, which are mainly entrained by metabolic cues, as it is the feeding pattern. This dynamic adaptation to nutrient accessibility applies completely to adiposemuscle tissue interaction: hormones that regulate adipose tissue lipolysis influence circulating fatty acid levels and fatty acids, in turn, regulate the choice of energy substrate in the muscle.

This glucose-fatty acids cycle is readily noted in the fed state consecutive to a high-fat meal or during exercise when plasma levels of fatty acids or ketone bodies dramatically rise, the non-oxidized glucose is converted to glycogen, which explains the fast muscle glycogen resynthesis after exercise. Redirecting glucose metabolism towards glycogen synthesis triggers the enhanced content of glycogen in muscles observed in hunger or diabetes.

The conversion of macroergic molecules' chemical energy into metabolically usable energy is strictly time-controlled by a sequence of variables including hormones, enzymatic complexes, and the presence of adequate cellular compartments needed to metabolize the three main classes of fuel molecules [23, 25].

Cells capable of metabolizing all types of nutrients select their food substrate for oxidation depending on the cells physiological status, adjusting between fed and fasting conditions. Several triggering signals dictate adaptation actions for each scenario, as it is the case of endocrine signals that have strong influences by switching determinant enzyme activity incredibly quickly, modulating gene expression profiles, dramatically altering the entire cellular metabolic profile $[31,50]$.

The nutritional influence on the circadian molecular equipment modulation

There is a clear relationship between human dietary behaviour and circadian clockwork. The regular feeding-fasting cycles represent dominant synchronizing signals for peripheral clocks by initiating a series of molecular entrainment pathways, able to conduct the circadian routine. In contrast, disrupted feeding schedules can fully uncouple peripheral oscillators from the master clock in the suprachiasmatic nucleus, reinforcing the statement that metabolic cues, modulated by diet, reach and signal the SCN and modify specific output pathways of the clock $[11,29]$.

For instance, the fibroblast growth factor 21, a liverderived starvation hormone with pleiotropic metabolic functions, binds to its receptors in the SCN to modulate glucocorticoid synthesis and adjust the locomotor activity. The SCN also expresses receptors for leptin and ghrelin, depicting the intimate relationship of these important hormones that regulate appetite and hunger signals with the hypothalamic area of control. Besides, the $\mathrm{SCN}$ is interconnected with other hypothalamic nuclei, like the arcuate nucleus, which conveys metabolic states to the SCN and regulates the feeding behaviour.

In peripheral tissues, nutritional characteristics and dietary timing have a profound influence on the circadian clock beyond the function of food as an entrainment cue. Mice fed a high-fat diet register massive circadian changes: their locomotor activity 
FARMACIA, 2019, Vol. 67, 4

modifies, their eating pattern is converted, and they ingest food almost equally throughout the day. Additionally, metabolite rhythmicity is disrupted in the serum, and the cellular expression of clockdependent genes becomes decontrolled. All these changes are noticeable only when food is provided ad libitum, time-restricted feeding preventing metabolic imbalances associated with a high-fat diet. Restricting food to the activity phase also improves pathological metabolic consequences in rat models of shift work $[38,69,74]$.

The effects of a high-fat diet on the peripheral clocks can be reversed by exchanging back to a low-fat diet, displaying the direct regulation of rhythmic gene expression by feeding-fasting cycles, driven rather by oscillating genes in liver than the core clock alone. It is though understandable that diets based on intermittent fasting regulate at a certain extent, the metabolic characteristics. Recently, the ketogenic diet has been proven to modulate of core clock gene expression in peripheral tissues $[11,80]$. There is a close relationship between activity stages and metabolism: daily cycles of action coordinate the feeding-fasting pattern, and recurrent feeding cues appear to be a dominant zeitgeber in metabolically responsive tissues. Additionally, factors that are having the potential to synchronize peripheral oscillators, as melatonin pulsatile secretion repressed by light, core body temperature adjustment with peak levels mid-day, high oxygen delivery rates to peripheral tissues during activity time or cyclic glucocorticoid production with peak levels early in the morning, are also determined by the SCN, and are all merged in a coherent strictly functional metabolic pathway.

The chronobiotic energy balance state and energy metabolism is depicted by the two separated phases that exist during a $24 \mathrm{~h}$ period: the activity and the rest periods. The activity time is characterized by energy gathering and food intake that results in energy harvesting, utilization, and storage, a period associated with high central and peripheral sensitivity to insulin and high glucose tolerance, elevated insulin secretion, high glucose uptake by the insulin-sensitive tissues, glycogen synthesis and hepatic and muscular glycolysis, obstruction of the hepatic gluconeogenesis, and increased lipogenesis and adiponectin production (Figure 3).

In opposition, during the rest/sleep phase of the day, prolonged fasting periods require the use of stored energy for maintaining the cellular homeostasis, insulin resistance patterns, emphasized hepatic gluconeogenesis and glycogenolysis, lipolysis, and leptin secretion. A series of hormones display circadian rhythmic fluctuations in their secretion and activity, among which glucocorticoids, the growth hormone and catecholamines. Melatonin, as the main endocrine circadian coordinating factor of the metabolic processes, prepares and modifies the central and peripheral metabolic tissues in order to respond to these hormones.

The circadian clock regulates gene expression and generally affects various organs and the network of neuroendocrine weight control signals. Overnight fasting, or fasting during sleeping hours, is associated with a nocturnal rise in plasma free fatty acids (FFA), ghrelin, growth hormone, and increased hepatic gluconeogenesis. The adipose tissue performs the cycling of triglycerides (TG) by controlling the uptake, esterification, and release of FFA to meet the metabolic demands of the liver and muscle tissue [65].

In multiple areas of metabolism, circadian rhythms are obvious: glucose and insulin synthesis, glucose tolerance, lipids levels, energy consumption patterns and appetite. Diurnal changes in peripheral insulin sensitivity, $\beta$-cell responsiveness, insulin clearance, and glucose efficient utilization seem to initiate the pulses in glucose metabolism. Likewise, diurnal changes in lipid synthesis, transport, and partitioning influence lipid periodic dynamics.

Expenditure of energy and appetite also reveal circadian rhythms, though not entirely driven by ghrelin or leptin. Quintessential anabolic rhythms are noticeable in humans early in the morning or around noon, glucose tolerance is optimal, skeletal muscle fatty acid oxidation and the thermic impact of food is more significant in the morning than in the night, leading to daytime being ideal for caloric intake and night time as ideal for resting and fasting, enhancing all secondary offensive mechanisms of glycaemic control and caloric balance, accordingly. On the other hand, the human circadian rhythm is not governed only by the day/night cycle. There is data in the literature and scientific studies demonstrating that a proper circadian rhythm modulates the function of organs. The most studied model is that of the liver due to its function important in maintaining energy homeostasis, being aware that it is under day-to-day diurnal storage and energy use. In this biological liver clock, developed as a mathematical model, AMP-activated protein kinase (AMPK) activity plays a role in the metabolic modulation of other peripheral clocks. This input clock may be a posttranscriptional way of regulating NAMPT (nicotinamide phosphoribosyl transferase) proteins through the action of AMPK. Therefore, AMP rhythms are essential for normal maintenance of the biological clock activity during the diurnal cycle. Interestingly, research groups were able to demonstrate the perturbations of the biological clock during feeding and fasting and how they can intervene pharmacologically at this point. This model can be transposed into current practice by developing models that include the rhythm of diet and exercise to combat metabolic pathologies $[17,68,85]$. 
FARMACIA, 2019, Vol. 67, 4

Significantly, affecting circadian rhythms impairs the metabolism and cause metabolic disease aetiology, suddenly declining glycaemic control, increasing the risk of obesity and type 2 diabetes. An acute circadian misalignment, for instance, may lift postprandial glucose concentrations by up to $20 \%$, suggesting that preserving circadian coordination is crucial for metabolic welfare [65].

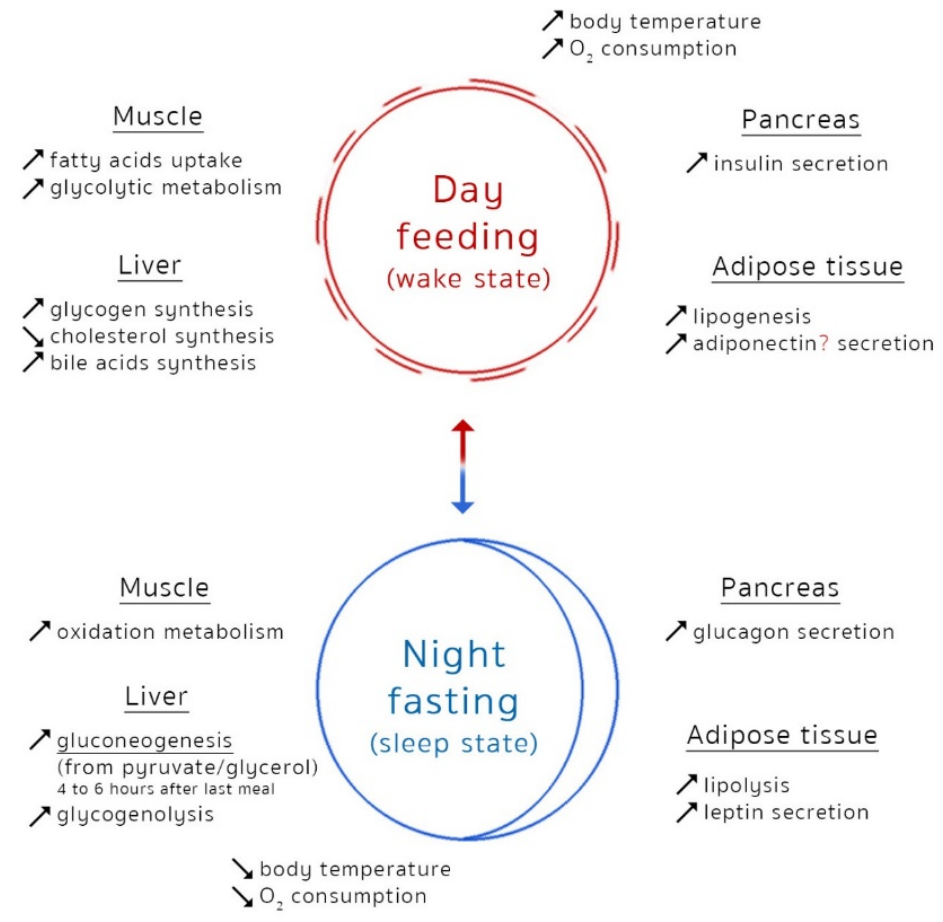

Figure 3.

The chronobiotic nature of metabolic processes and endocrine patterns, the essential modulator of the energetic balance

It is essential to understand whether improvements in circadian alignment can undeniably suppress or restore metabolic imbalances, revealing circadian system complex relationships with metabolism and dietary patterns. In combination with external environmental variables, ageing and pathological conditions, the significance of circadian metabolism regulation should be considered in order to obtain a sequence of evidence designed to prevent and therapeutically manage type 2 diabetes, obesity and cardiometabolic disorders [65].

The circadian interplay between nutritional, metabolic and endocrine factors

Melatonin, the pineal hormone, is a key mediator molecule that encompasses the integration of the cyclic environmental signals and the circadian distribution of physiological and behavioural processes, conducting an emblematic role in energy balance and body weight regulation throughout the entire day, despite its unique nocturnal synthesis profile. Following the functional particularities of the human system that controls the pineal melatonin production, it can be surely stated that the physiological system that controls melatonin synthesis coordinates metabolic pathways, gene expression of main regulatory enzymes and energy expenditure according to the duration of the daily scotoperiod, also depicting the seasonal characteristics within a year and acting as a neuroendocrine mediator $[5,63]$.

Human organisms are physiologically constructed to acquire energy, by nutritional intake and metabolic processing, in the active phase of the day and to mobilize stored energy in the resting phase, being able to sustain all living cells actively. Another important aspect is represented by it is own and extremely powerful antioxidant mechanism driven concomitantly in order maintain a steady-state oxidative status, due to the high level of reactive oxygen species acquired throughout the intense cellular processes. Physiological or pathological states related with melatonin synthesis decline, like ageing, shift work or environmental lighting during the night and diabetes, conduct to a series of pathological consequences which are mainly clustered in the metabolic syndrome components, like obesity, insulin resistance, cardiovascular malfunction, and hypertension $[15,20]$. 
FARMACIA, 2019, Vol. 67, 4

It is obvious the intimate signalling relationship between melatonin and insulin, the main regulatory pancreatic hormone, first exposed in the medical history by the Romanian research group of professor Constantin Parhon, in 1939 and later by its collaborators [54, 61].

In conjunction with post-meal variation, insulin secretion from the pancreatic cells into the portal veins is characteristically pulsatile, reflecting a diurnal oscillatory pattern. Insulin secretion is biphasic: reacting to a stimulus, mostly depicted by glucose, it presents an initial fast release stage, followed by a less intense but more prolonged discharge of the hormone. Insulin secretion may be affected by changes in synthesis represented by gene transcription, translation, and post-translational alterations, as well as by variables affecting insulin release from secretory granules. Given the crucial role of insulin in glucose metabolism, it is not surprising that glucose has numerous impact figures on insulin biosynthesis and secretion, primarily through nutritional sources [19, 22, 70].

On the other hand, the pineal indoleamine induces IGF-1 (insulin-like growth factor 1) receptor phosphorylation, conducting to the integrity of islet cells, and it enhances the glucagon synthesis, all synchronizing the pancreas metabolic rhythms with the activity-feeding versus rest-fasting states.

The high insulin-to-glucagon ratio of the postabsorptive state promotes lipid and carbohydrate storage. In contrast, a high glucagon-to-insulin ratio, characteristic of the fasted state, stimulates adipose tissue lipolysis and hepatic glucose production to preserve glucose supply to those tissues that rely exclusively on this monosaccharide.

Sleep-wake cycles in gene expression modulation Sleep is a metabolic master switch, and the sleepwake cycle control is the most effective mean of aligning the organism with the circadian flow. Of course, from a metabolic point of perspective, the distribution of energy varies substantially between sleep and wakefulness. Studies in humans have shown that energy expenditure during sleep is decreased to $60 \%$ compared to the wakefulness phase and while the sleep phase results in a small decrease in total daily energy expenditure, the overall energy saved and mainly through motility functions can be redistributed to regenerative, adaptive, protective and anabolic mechanisms such as immune functions, synaptic plasticity and glycogen synthesis. Furthermore, the rhythm of sleep-awake inevitably determines the feeding and fasting pattern and thus sets the timeline hierarchy in peripheral tissues through nutrient concentrations and a range of associated parameters such as energy accessibility and redox status $[17,18,23]$.

There are absolute proofs that metabolism is more than a circadian clock output feature. Metabolic variables are also powerful controllers of circadian oscillators, and this feedback regulation is evolving mechanisms point to interactions between discrete metabolites and their cellular binding sites. These are often referred to as metabolic sensor proteins that identify changes in the concentrations of nutrients, energy and redox status and change the patterns of gene expression.

The most significant evolutionary energy sensor is the metabolite acetyl-CoA, which links carbohydrate, lipid and amino acid metabolism. In mammals, gene expression is profoundly affected by rates of histone acetylation, and the necessary acetyl-CoA is derived from the acetyl-CoA cytoplasmic and nuclear pools that generate ATP-citrate lyase and acetyl-CoA synthetase enzymes. Acetyl-CoA controls transcription and post-transcription phenomena as a substrate for histone and non-histone protein acetylation, and this post-translational alteration affects enzyme concentrations and activities.

\section{Feeding regimens, circadian rhythmicity and metabolic programming}

The master and peripheral clocks are in close interdependence with the metabolic regimens that are tightly controlled by the feeding patterns, nutritional metabolites and hormones secretion that is also reliant on food availability. Several animal studies have assessed different food regimens in order to delineate the reflection of the nutrition pattern within the profound biochemical pathways and the inner biological clock $[9,17,25,51,53]$.

Restricted feeding portrays a dietary regimen that limits the time and length of the supply of food without reducing calories. Experimental studies carried out on animals receiving food ad libitum every day for only a few hours, but at the same time, showed that they customize to the feeding period within a few days and ingest their daily ratio of food during that limited time, culminating in profound effects on animals behaviour and physiology [24, 62, 78]. Animals exhibit anticipatory food behaviour two to four hours before the meal, demonstrated by increased locomotor activity, body temperature, corticosterone secretion, gastrointestinal motility and digestive enzymatic activity, identified as biological clock output mechanisms $[41,76]$.

Restricted feeding dominates the SCN and generates time-dependent patterns in arrhythmic, clock mutant mice or lesioned SCN animals, regardless of the lighting settings $[36,42,55,60,76]$. Restricted feeding has no impact on the central pacemaker in the SCN but alters the secondary oscillators from peripheral tissues such as liver, kidney, heart, and pancreas $[13,17,36,40,60,71,77]$. Restricted feeding disassociates the SCN from the periphery, indicating that dietary regulation of peripheral 
tissue clock oscillators may play a significant role in coordinating metabolic fluctuations [47]. Many of the physiological operations usually dictated by the SCN master clock, such as the body temperature, locomotor activity and heart rate, are adapted to the moment of food accessibility [10, 26,27, 36, 39, 55]. The SCN clock, whose function remains unaffected, resets the peripheral oscillators as readily as the supply of food returns to normal [17].

Calorie restriction is a nutritional regime low in calories without conducting to malnutrition. Calorie restriction limits the number of calories resulting from carbohydrates, fats, or proteins to $60-75 \%$ of the normal animals' diet. Several studies outlined that calorie restriction significantly extends the life span of rodents by up to $50 \%$, and also delays the occurrence of age-associated pathophysiological changes, such as cancer, diabetes, kidney disease, and cataract $[49,68]$.

In direct opposition to restricted feeding, calorie restriction entrains the master suprachiasmatic clock, demonstrating that this particular nutritional sequence could affect the central oscillator: during the daytime, it distresses the temporal organization of the $\mathrm{SCN}$ clockwork and circadian outputs in mice under a light-dark cycle. Further, calorie restriction interacts with the photic responses of the circadian system, indicating that the energy metabolism modulates gating of photic inputs in mammals [14, 28, 52, 66]. Intermittent fasting assures ad libitum food availability every other day, and studies have concluded that intermittently fasted mice eat on the days they have access to food roughly twice as much as those having permanent access to food [3, 19].

Correspondingly to calorically restricted animals, intermittent fasted animals display augmented life span in comparison with the ad libitum-fed control as well as balanced glucose metabolism, cardiac and neuronal protection, and increased resistance to cancer $[1,3,16,19,31,48,50,51,72]$. The intermittent fasting-induced favourable effects are assumed to occur autonomously of the global caloric intake, a suggested mechanism is the stimulation of cellular stress pathways induced by this dietary regimen $[3$, 50, 51]. Intermittent fasting can affect circadian rhythms in a different way depending on the timing of food availability, suggesting that this regimen affects the SCN clock, similarly to calorie restriction.

$\mathrm{SCN}$ resetting by intermittent fasting and calorie restriction might be the answer to many chronobiologic misalignments, accounting numerous proofs for the health benefits conferred by these regimens.

\section{Conclusions}

Understanding the physiological and pathological foundations that grant individuality in response to diet and nutritional behaviour is essential in advancing in the field of metabolic diseases and cancer therapy. This comprises revealing the gene expression characteristics that are intermediated by genomic programming through epigenetic DNA alterations. Highly susceptible epigenetic landscapes are subjective to a series of modulatory factors as age, genetic heritage, stress environmental elements, dietary exposure outline and nutritional status. Epigenetic adjustments influence transcription processes and genome steadiness modulates developmental and reparatory mechanisms, having life-long consequences.

\section{Acknowledgement}

This paper was financially supported by "Carol Davila" University of Medicine and Pharmacy through Contract no. CNFIS-FDI-2019-0534 (MEDEX-II) funded by the Ministry of National Education of Romania, from the Institutional Development Fund for Public Universities - FDI 2019.

\section{References}

1. Ahmet I, Wan R, Mattson MP, Lakatta EG, Talan $\mathrm{M}$, Cardioprotection by intermittent fasting in rats. Circulation, 2005; 112: 3115-3121.

2. Allison KC, Goel N, Timing of eating in adults across the weight spectrum: Metabolic factors and potential circadian mechanisms. Physiol Behav., 2018; 192: 158-166.

3. Anson RM, Guo Z, de Cabo R, Iyun T, Rios M, Hagepanos A, Ingram DK, Lane MA, Mattson MP, Intermittent fasting dissociates beneficial effects of dietary restriction on glucose metabolism and neuronal resistance to injury from calorie intake. Proc Natl Acad Sci USA, 2003; 100: 6216-6220.

4. Anton SD, Moehl K, Donahoo WT, Marosi K, Lee SA, Mainous AG $3^{\text {rd }}$, Leeuwenburgh $\mathrm{C}$, Mattson MP, Flipping the metabolic switch: Understanding and applying the health benefits of fasting. Obesity, 2018; 26: 254-268.

5. Arsene AL, Mitrea N, Cristea A, Drăgoi CM, Experimental research on mice regarding the implication of melatonin in pain management. Farmacia, 2009; 57(2): 223-228.

6. Asher G, Sassone-Corsi P, Time for food: The intimate interplay between nutrition, metabolism, and the circadian clock. Cell, 2015; 61: 84-92.

7. Barbu CG, Arsene AL, Florea S, Albu A, Sirbu A, Martin S, Nicolae AC, Burcea-Dragomiroiu GTA, Popa DE, Velescu BS, Dumitrescu IB, Mitrea N, Draganescu D, Lupuliasa D, Spandidos DA, Tsatsakis AM, Dragoi CM, Fica S, Cardiovascular risk assessment in osteoporotic patients using osteoprotegerin as a reliable predictive biochemical marker. Mol Med Rep., 2017;16(5): 6059-6067.

8. Berg JM, Tymoczko JL, Stryer L, Biochemistry $5^{\text {th }}$ edition. New York: W H Freeman; 2002.

9. Bi S, Wang H, Kuang W, Stem cell rejuvenation and the role of autophagy in age retardation by caloric restriction: An update. Mech Ageing Dev., 2018; 175: 46-54. 
FARMACIA, 2019, Vol. 67, 4

10. Boulamery-Velly A, Simon N, Vidal J, Mouchet J, Bruguerolle B, Effects of three-hour restricted food access during the light period on circadian rhythms of temperature, locomotor activity, and heart rate in rats. Chronobiol Int., 2005; 22: 489-498.

11. Branecky KL, Niswender KD, Pendergast JS, Disruption of daily rhythms by high-fat diet is reversible. PLoS One, 2015; 10(9): 1-12.

12. Cardone L, Hirayama J, Giordano F, Tamaru T, Palvimo JJ, Sassone-Corsi P, Circadian clock control by SUMOylation of BMAL1. Science, 2005; 309: 1390-1394.

13. Cassone VM, Stephan FK, Central and peripheral regulation of feeding and nutrition by the mammalian circadian clock: implications for nutrition during manned space flight. Nutrition, 2002; 18: 814-819.

14. Challet E, Caldelas I, Graff C, Pe'vet P, Synchronization of the molecular clockwork by light- and food-related cues in mammals. Biol Chem., 2003; 384: 711-719.

15. Cipolla Neto J, Amaral FG, Afeche SC, Tan DX, Reiter RJ, Melatonin, energy metabolism, and obesity: a review. J Pineal Res., 2014; 56: 371-381.

16. Ciocirlan M, Draghia L, Manuc, Daniela D, PanteaStoian A, Cazan AR, Husar-Sburlan I, Dutei CA, Ciocirlan M, Monica PC, Diculescu M, Manuc M, Nutritional status of patients with digestive cancers. $3^{\text {rd }}$ International Conference on Interdisciplinary Management of Diabetes Mellitus and its Complications - INTERDIAB. Proceedings. 2017; 132-138.

17. Damiola F, Le Minh N, Preitner N, Kornmann B, FleuryOlela F, Schibler U, Restricted feeding uncouples circadian oscillators in peripheral tissues from the central pacemaker in the suprachiasmatic nucleus. Genes Dev., 2000; 14: 2950-2961.

18. Davidson AJ, Search for the feeding-entrainable circadian oscillator: a complex proposition. $\mathrm{Am} \mathrm{J}$ Physiol Regul Integr Comp Physiol., 2006; 290: R1524-R1526.

19. Descamps O, Riondel J, Ducros V, Roussel AM Mitochondrial production of reactive oxygen species and incidence of age-associated lymphoma in OF1 mice: effect of alternate-day fasting. Mech Ageing Dev., 2005; 126: 1185-1191.

20. Drăgoi CM, Arsene A, Dinu-Pîrvu CE, Dumitrescu IB, Popa DE, Burcea Dragomiroiu GTA, Udeanu DI, Timnea O, Velescu BS, Nicolae AC- Melatonin, a silent regulator of the glucose homeostasis, "Carbohydrate" Book edited by Caliskan M, Kavaklı H, Öz GC, InTech - Rijeka, Croația, 2016.

21. Drăgoi CM, Mitrea N, Arsene AL, Ilie M, Nicolae AC, Jurkat E6.1 cell line studies regarding the effects of some bio-indols on the membrane fluidity. Farmacia, 2012; 60(1): 13-20.

22. Drăgoi CM, Nicolae AC, Grigore C, Dinu-Pîrvu CE, Arsene AL, Characteristics of glucose homeostasis and lipidic profile in a hamster metabolic syndrome model, after the co-administration of melatonin and irbesartan in a multiparticulate pharmaceutical formulation, $2^{\text {nd }}$ International Conference on Interdisciplinary Management of Diabetes Mellitus and its Complications - INTERDIAB. Proceedings. Niculescu Publishing House, 2016; 221-229.
23. Drăgoi CM, Nicolae AC, Dumitrescu IB, Popa DE, Ritivoiu M, Arsene AL, DNA targeting as a molecular mechanism underlying endogenous indoles biological effects. Farmacia, 2019; 67(2): 367-377.

24. Feillet CA, Ripperger JA, Magnone MC, Dulloo A, Albrecht U, Challet E, Lack of food anticipation in Per2 mutant mice. Curr Biol., 2006; 16: 2016-2022.

25. Fontana L, Nehme J, Demaria M, Caloric restriction and cellular senescence. Mech Ageing Dev., 2018; 176: 19-23.

26. Froy O, The relationship between nutrition and circadian rhythms in mammals. Front Neuroendocrinol., 2007; 28: 61-71.

27. Froy O, Chapnik N, Miskin R, Effect of intermittent fasting on circadian rhythms in mice depends on feeding time. Mech Ageing Dev., 2009; 130: 154-160.

28. Froy O, Circadian rhythms, metabolism, and obesity. Endocrine Reviews, 2010; 31(1): 1-24.

29. Gabel K, Hoddy KK, Haggerty N, Song J, Kroeger CM, Trepanowski JF, Panda S, Varady KA, Effects of 8-h time restricted feeding on body weight and metabolic disease risk factors in obese adults: A pilot study. Nutr Healthy Aging, 2018; 4: 345-353.

30. Gasior M, Rogawski MA, Hartman AL, Neuroprotective and diseasemodifying effects of the ketogenic diet. Behav Pharmacol., 2006; 17: 431-439.

31. Goodrick CL, Ingram DK, Reynolds MA, Freeman JR, Cider N, Effects of intermittent feeding upon body weight and lifespan in inbred mice: interaction of genotype and age. Mech Ageing Dev., 1990; 55: 69-87.

32. Gooley JJ, Schomer A, Saper CB, The dorsomedial hypothalamic nucleus is critical for the expression of foodentrainable circadian rhythms. Nat Neurosci., 2006; 9: 398-407.

33. Grasl-Kraupp B, Bursch W, Ruttkay-Nedecky B, Wagner A, Lauer B, Schulte-Hermann R, Food restriction eliminates preneoplastic cells through apoptosis and antagonizes carcinogenesis in rat liver. Proc Natl Acad Sci USA, 1994; 91: 9995-9999.

34. Green CB, Takahashi JS, Bass J, The meter of metabolism. Cell, 2008; 134: 728-742.

35. Gruia V, Aramă C, Mitrea N, Arsene AL, Grădinaru $\mathrm{D}$, Drăgoi CM, The HPLC plasmatic profile of some fat-soluble antioxidant micronutrients (all-trans-retinol, $\alpha$-tocopherol, coenzime Q10) in diabetic and dyslipidemic patients. Farmacia, 2009; 57(5): 630-638.

36. Hara R, Wan K, Wakamatsu H, Aida R, Moriya T, Akiyama M, Shibata S, Restricted feeding entrains liver clock without participation of the suprachiasmatic nucleus. Genes Cells., 2001; 6: 269-278.

37. Hasselbalch SG, Madsen PL, Hageman LP, Olsen KS, Justesen N, Holm S, Paulson OB, Changes in cerebral blood flow and carbohydrate metabolism during acute hyperketonemia. Am J Physiol., 1996; 270: E746-E751.

38. Hatori M, Vollmers C, Zarrinpar A, DiTacchio L, Bushong EA, Gill S, Leblanc M, Chaix A, Joens M, Fitzpatrick JA, Ellisman MH, Panda S, Timerestricted feeding without reducing caloric intake prevents metabolic diseases in mice fed a high-fat diet. Cell Metab., 2012; 15(6): 848-860.

39. Hirao J, Arakawa S, Watanabe K, Ito K, Furukawa T, Effects of restricted feeding on daily fluctuations of 
hepatic functions including p450 monooxygenase activities in rats. J Biol Chem., 2006; 281: 3165-3171.

40. Hirota T, Fukada Y, Resetting mechanism of central and peripheral circadian clocks in mammals. Zoolog Sci., 2004; 21: 359-368.

41. Honma KI, Honma S, Hiroshige T, Critical role of food amount for prefeeding corticosterone peak in rats. Am J Physiol., 1983; 245: R339-R344.

42. Horikawa K, Minami Y, Iijima M, Akiyama M, Shibata $\mathrm{S}$, Rapid damping of food-entrained circadian rhythm of clock gene expression in clock-defective peripheral tissues under fasting conditions. Neuroscience, 2005; 134: 335-343.

43. Kessler K, Hornemann S, Petzke KJ, Kemper M, Markova M, Rudovich N, Grune T, Kramer A, Pfeiffer AFH, Pivovarova-Ramich O, Diurnal distribution of carbohydrates and fat affects substrate oxidation and adipokine secretion in humans. Am J Clin Nutr., 2018; 108: 1209-1219.

44. Kohsaka A, Bass J, A sense of time: how molecular clocks organize metabolism. Trends Endocrinol Metab., 2007; 18: 4-11.

45. La Fleur SE, Daily rhythms in glucose metabolism: suprachiasmatic nucleus output to peripheral tissue. J Neuroendocrinol., 2003; 15:315-322.

46. Landry GJ, Simon MM, Webb IC, Mistlberger RE. Persistence of a behavioral food-anticipatory circadian rhythm following dorsomedial hypothalamic ablation in rats. Am J Physiol Regul Integr Comp Physiol., 2006; 290: R1527-R1534.

47. Lin JD, Liu C, Li S, Integration of energy metabolism and the mammalian clock. Cell Cycle, 2008, 7: 453-457.

48. Mager DE, Wan R, Brown M, Cheng A, Wareski $\mathrm{P}$, Abernethy DR, Mattson MP, Caloric restriction and intermittent fasting alter spectral measures of heart rate and blood pressure variability in rats. FASEB J., 2006; 20: 631-637.

49. Masoro EJ, Overview of caloric restriction and ageing. Mech Ageing Dev., 2005; 126: 913-922.

50. Mattson MP, Dietary factors, hormesis and health. Ageing Res Rev., 2008; 7: 43-48.

51. Mattson MP, Duan W, Wan R, Guo Z, Prophylactic activation of neuroprotective stress response pathways by dietary and behavioral manipulations. NeuroRx., 2004; 1: 111-116.

52. Mendoza J, Graff C, Dardente H, Pevet P, Challet E, Feeding cues alter clock gene oscillations and photic responses in the suprachiasmatic nuclei of mice exposed to a light/dark cycle. $J$ Neurosci., 2005; 25: 1514-1522.

53. Mieda M, Williams SC, Richardson JA, Tanaka K, Yanagisawa M, The dorsomedial hypothalamic nucleus as a putative food-entrainable circadian pacemaker. Proc Natl Acad Sci USA., 2006; 103: 12150-12155.

54. Milcu SM, Role de l'épiphyse dans le metabolisme glucidique. J Annu Diabetol Dieu., 1968; 9: 163-180.

55. Mistlberger RE, Circadian rhythms: perturbing a food-entrained clock. Curr Biol., 2006; 16: R968R969.

56. Mohamad MA, Mitrea N, Nicolae AC, Constantinescu MZ, Drăgoi CM, Arsene AL, Barbu CG, The dynamics of adiponectin and leptin on metabolic syndrome patients and age matched healthy subjects. Farmacia, 2014; 62(3): 532-545.

57. Moran C, Beare R, Phan TG, Type 2 diabetes mellitus and biomarkers of neurodegeneration. Neurology, 2015; 85(13): 1123-1130.

58. Nicolae AC, Arsene AL, Vuță V, Popa DE, Sîrbu CA, Burcea Dragomiroiu GTA, Dumitrescu IB, Velescu BS, Gofiță E, Drăgoi CM, In vitro P-gp expression after administration of CNS active drugs. Farmacia, 2016; 64(6): 844-850.

59. Nicolae AC, Mitrea N, Arsene AL, Constantinescu MZ, Vuță V, Drăgoi CM, In vitro P-glycoprotein inhibition assay on N2a murine cell line. Farmacia, 2013; 61(3): 481-491.

60. Oishi K, Miyazaki K, Ishida N, Functional CLOCK is not involved in the entrainment of peripheral clocks to the restricted feeding: Entrainable expression of mPer2 and Bmal1 mRNAs in the heart of clock mutant mice on Jcl: ICR background. Biochem Biophys Res Commun., 2002; 298: 198-202.

61. Parhon, CI, Congrès d'Endocrinologie de Bucarest. 1939; I: 187.

62. Pendergast JS, Nakamura W, Friday RC, Hatanaka F, Takumi T, Yamazaki S, Robust food anticipatory activity in BMAL1-deficient mice. PLOS ONE, 2009; 4(3): 1-9.

63. Peschke E, Bähr I, Mühlbauer E, Melatonin and pancreatic islets: interrelationships between melatonin, insulin and glucagon. Int J Mol Sci., 2013; 14(4): 6981-7015.

64. Puchalska P, Crawford PA, Multi-dimensional roles of ketone bodies in fuel metabolism, signaling and therapeutics. Cell Metab., 2017; 25(2): 262-284.

65. Reinke H, Asher G, Crosstalk between metabolism and circadian clocks. Nat Rev Mol Cell Biol., 2019; 20: $227-241$.

66. Resuehr D, Olcese J, Caloric restriction and melatonin substitution: effects on murine circadian parameters. Brain Res., 2005; 1048: 146-152.

67. Roenneberg T, Kantermann T, Juda M, Vetter C, Allebrandt $\mathrm{KV}$, Light and the human circadian clock. In: Kramer A., Merrow M. (eds) Circadian Clocks. Handbook of Experimental Pharmacology, Springer, Berlin, Heidelberg, 2013, 217.

68. Saini C, Liani A, Curie T, Gos P, Kreppel F, Bonacina L, Wolf JP, Poget YA, Franken P, Schibler U, Realtime recording of circadian liver gene expression in freely moving mice reveals the phase-setting behavior of hepatocyte clocks. Genes Dev., 2013; 27: 1526-1536.

69. Salgado-Delgado R, Angeles-Castellanos M, Saderi N, Buijs RM, Escobar C, Food intake during the normal activity phase prevents obesity and circadian desynchrony in a rat model of night work. Endocrinology, 2010; 151: 1019-1029.

70. Sanders LM, Carbohydrate: Digestion, Absorption and Metabolism. Encyclopedia of Food and Health, 2016; 643-650.

71. Schibler U, Ripperger J, Brown SA, Peripheral circadian oscillators in mammals: time and food. $J$ Biol Rhythms., 2003; 18: 250-260.

72. Sharma S, Kaur G, Neuroprotective potential of dietary restriction against kainate-induced excitotoxicity in adult male Wistar rats. Brain Res Bull., 2005; 67: 482-491. 
73. Shen J, Tanida M, Niijima A, Nagai K. In vivo effects of leptin on autonomic nerve activity and lipolysis in rats. Neurosci Lett., 2007; 416: 193-197.

74. Sherman H, Timed high-fat diet resets circadian metabolism and prevents obesity. FASEB J., 2012; 26: 3493-3502.

75. Sîrbu CA, Drăgoi CM, Nicolae AC, Pleșa CF, History of Interferon treatments in multiple sclerosis-60 years of progress. Farmacia, 2017; 65(1): 14-18.

76. Stephan FK, The "other" circadian system: food as a Zeitgeber. J Biol Rhythms., 2002; 17: 284-292.

77. Stokkan KA, Yamazaki S, Tei H, Sakaki Y, Menaker $\mathrm{M}$, Entrainment of the circadian clock in the liver by feeding. Science, 2001; 291: 490-493.

78. Storch KF, Weitz CJ, Daily rhythms of foodanticipatory behavioral activity do not require the known circadian clock. Proc Natl Acad Sci USA, 2009; 106: 6808-6813.

79. Tarţa-Arsene O, Leanca M, Dică A, Bran E, Rad F, Timnea O, Păcurar D, Velescu BS, Nicolae AC, Drăgoi CM, Dietary omega-3 Fatty acids supplimentation for attention deficit with hyperactivity disorder in epileptic children. Farmacia, 2017; 65(4): 550-556.

80. Tognini P, Murakami M, Liu Y, Eckel-Mahan KL, Newman JC, Verdin E, Baldi P, Sassone-Corsi P, Distinct circadian signatures in liver and gut clocks revealed by ketogenic diet. Cell Metab., 2017; 26: 523-538.

81. Vitaterna MH, King DP, Chang AM, Kornhauser JM, Lowrey PL, McDonald JD, Dove WF, Pinto
LH, Turek FW, Takahashi JS, Mutagenesis and mapping of a mouse gene, Clock, essential for circadian behavior. Science, 1994; 264: 719-725

82. Voiculescu SE, le Duc D, Roșca AE, Zeca V, Chiţimuş DM, Arsene AL, Drăgoi CM, Nicolae AC, Zăgrean L, Schöneberg T, Zăgrean AM, Behavioral and molecular effects of prenatal continuous light exposure in the adult rat. Brain Res., 2016; 1650: 51-59.

83. Wefers J, van Moorsel D, Hansen J, Connell NJ, Havekes B, Hoeks J, van Marken Lichtenbelt WD, Duez H, Phielix E, Kalsbeek A, Boekschoten MV, Hooiveld GJ, Hesselink MKC, Kersten S, Staels B, Scheer FAJL, Schrauwen P, Circadian misalignment induces fatty acid metabolism gene profiles and compromises insulin sensitivity in human skeletal muscle. Proc Natl Acad Sci USA, 2018; 115: 77897794.

84. White H, Venkatesh B, Clinical review: Ketones and brain injury. Critical Care, 2011; 15(2): 1-10.

85. Woller A, Duez H, Staels B, Lefranc M, A mathematical model of the liver circadian clock linking feeding and fasting cycles to clock function. Cell Rep., 2016; 17(4): 1087-1097.

86. Ye $\mathrm{K}, \mathrm{Gu} \mathrm{Z}$, Recent advances in understanding the role of nutrition in human genome evolution. $A d v$ Nutr., 2011; 2: 486-496.

87. Yudkoff M, Daikhin Y, Nissim I, Lazarow A, Ketogenic diet, amino acid metabolism, and seizure control. J Neurosci Res., 2001; 66: 931-940. 